\title{
Geomechanics of rock array for chamber system of coal deposits development on the example of finalizing by KGRP complex
}

\author{
Alexey Bykadorov ${ }^{1, *}$, Dmitry Degtyarev ${ }^{1}$, Sergey Smirnov ${ }^{2}$, and Oleg Pechenegov ${ }^{2}$ \\ ${ }^{1}$ LLC SIGI (Siberian Institute of Geotechnical Research), 653033, Prokopievsk, 11 Gagarina st., \\ Russian Federation \\ ${ }^{2}$ Resourse Ltd., 654004, Novokuznetsk, 13 Schorsa st., Russian Federation
}

\begin{abstract}
The results of systematic instrumental observations of Earth's surface's subsidence which was undermined by SHM (Superior Highwall Miners) are given. The regularities of subsidence are revealed. The empirical relationships are established. The methodical provisions for calculating the expected displacements and deformations of the undermined earth's surface are given.
\end{abstract}

\section{Introduction}

This article presents the results of the first systematic instrumental observations in the section of LTD "Resource" in the coal mining on Taldinskoye coal deposit concentrated among the marginal technical and licensing boundaries. The first systematic observations were made in finalizing seam " 68 ". Observation station consisted of five ground frames. More extensive instrumental observations were made in the finalization of seam 70 .

\section{Materials and Methods}

The thickness of seam " 70 " varies from $4 \mathrm{~m}$ to $5.7 \mathrm{~m}$, with the average $4.7 \mathrm{~m}$, false roof is absent, in the immediate roof lies siltstone or sandstone with a compressive strength 44.8 $\mathrm{MPa}$ and $67.8 \mathrm{MPa}$ respectively and unstable rock layer $1 \mathrm{~m}$. In the soil of coal seam there is siltstone formation with the compressive strength $44.8 \mathrm{MPa}$, the average dip angle is 200 , the depth of mining works is up to $108 \mathrm{~m}$.

The coal deposit development of seam "70" by KGRP complex on the site of "Dumping Deep South 2" is carried out in 2 layers. The width of the chambers, inter-chamber and block pillars are respectively $3.5 \mathrm{~m}, 2.0 \mathrm{~m}$ and $5.5 \mathrm{~m}$; the distance between the block pillars is $48 \mathrm{~m}$ (9 cameras).

Measurements on observation stations were made by coordinate measurements with the direct determination of coordinates in the field on the instrument's built-in electronic

\footnotetext{
* Correspondent author: sibigi@mail.ru
} 
program with post-processing GPS surveying equipment in software systems "Magnet Field" [1-3] and "Credo-DAT" [4-6].

Visual and instrumental observations have revealed that the collapse of undermined rock mass occurred with some landing step during one day at almost maximum amount of subsidence. The value of the shrinkage between steps of collapse is from 2 to $6 \%$ of maximum subsidence of the array for different extent of undermining. On the Earth's surface the cauldron appears trough displacement (subsidence), a fragment of which is presented in Fig. 1. Under the subsequent subsidence the cauldron moves after the collapse, almost without changing its profile. Thus, as seen in Fig. 1, there is a part of undermining of the power lines and the road.

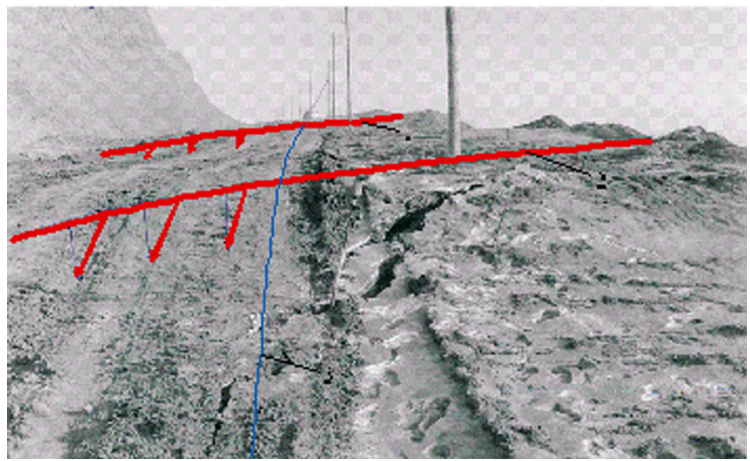

Fig. 1. The cauldron at the site of the first bench after the first subsidence of undermined array: 1 - the beginning of displacement between 6 and 5 benchmarks; 2 - the cauldron near the fifth frame; 3 - the cauldron's profile.

On the surface of the first bench there are concentrated deformations like cracks (Fig. 2) up to $20 \mathrm{~cm}$. At the site of the second bench there is none of these deformations.

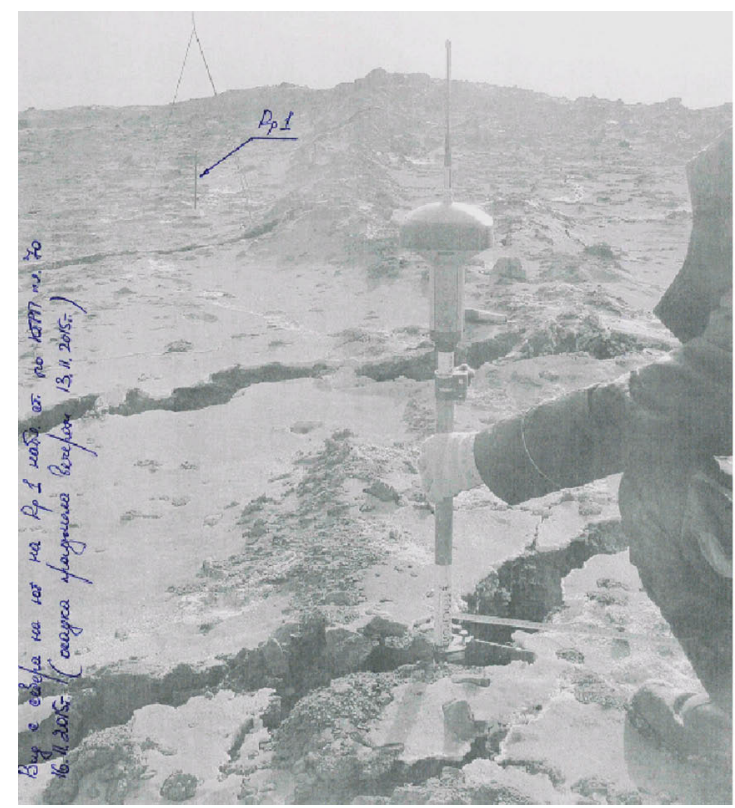

Fig. 2. Concentrated deformations of the array (cracks) at the site of the first bench in the area of the first frame. 
Fig. 3 shows intact array on the site of the first bench, and Fig. 4 shows the fragment of collapsed array. Directly above the workings there are visible cracks and fractures, from which the blocks of undermined array subside. The overlying array (the side of the second bench) subsides almost without vertical and inclined cracks.

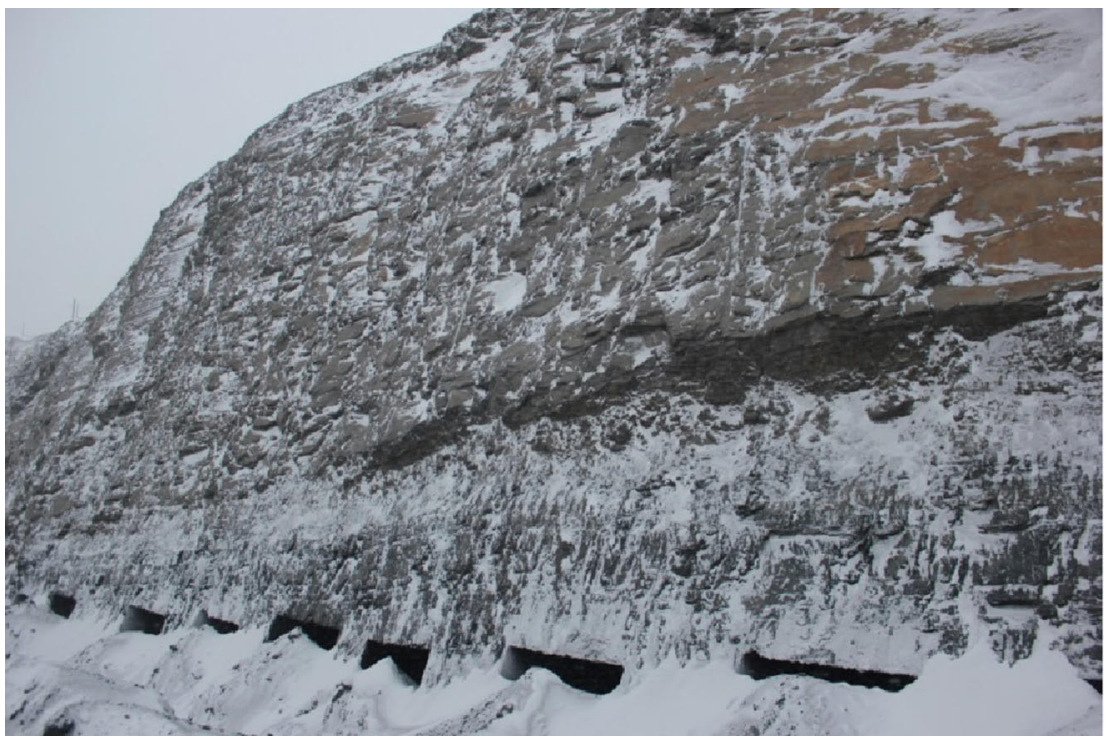

Fig 3. The intact site of the first bench.

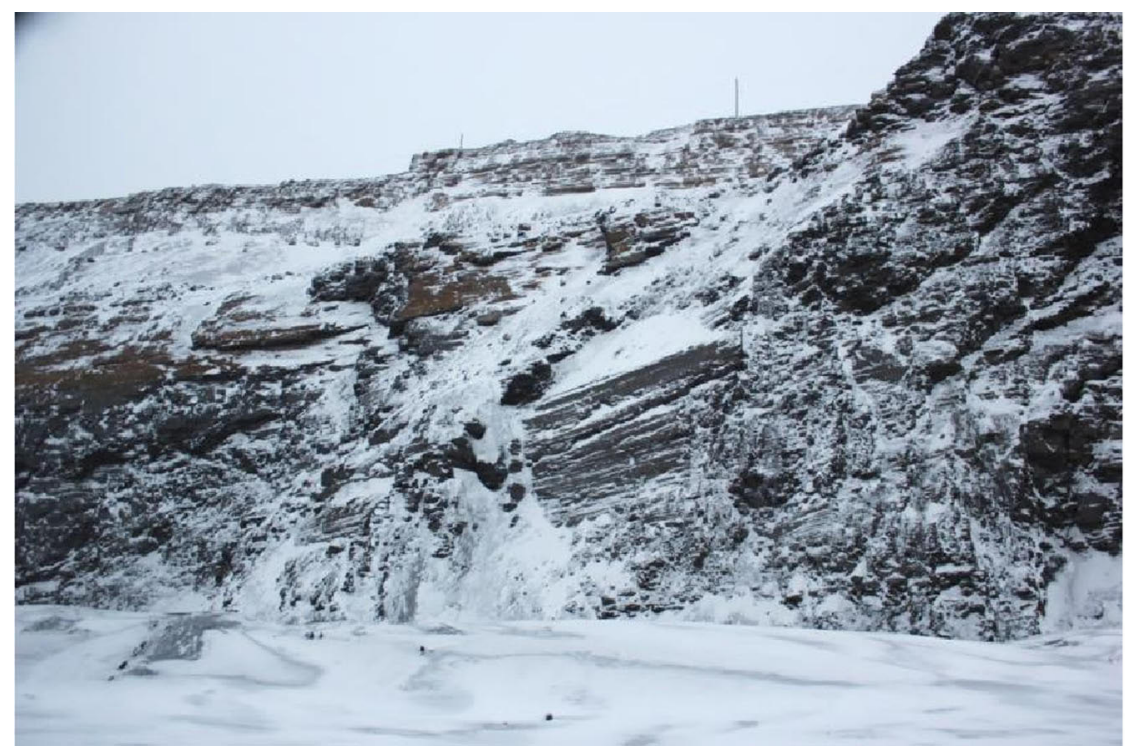

Fig 4. The site of the first bench in the collapse area.

The example of cauldron on the Earth's surface at the site of the first bench on the profile line L1 in finalizing seam "70" is shown in Fig. 5. 


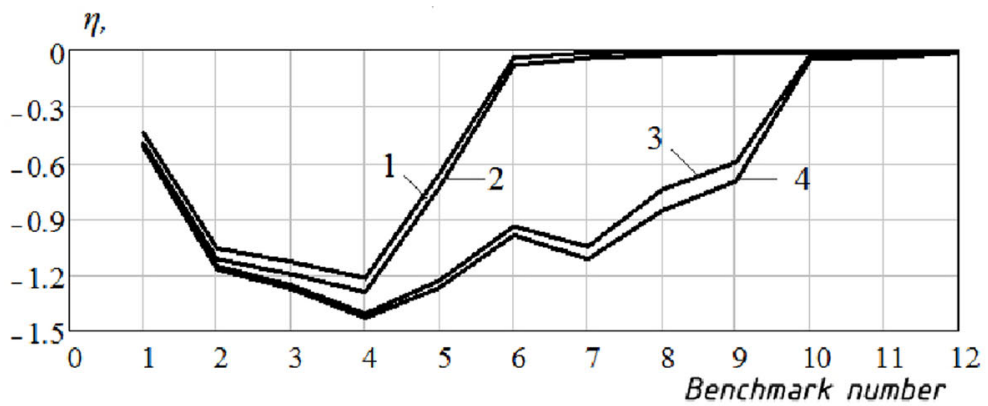

Fig. 5. Genesis of cauldron in finalizing seam "70": 1 - the cauldron in the first collapse of the array; 2 - array post-subsidence between the first and second subsidences; 3 - the cauldron of array secondary displacement; 4 - post-subsidence of the array to the next subsidence.

\section{Results and Discussion}

Instrumental studies showed that at different extents of array undermining, depending on the ratio of collapse along the strike of the seam to an average depth of mining, the maximum subsidence of the surface can be determined by formula (1), considering the ratio of equivalent extracting capacity $K_{e}$ :

$$
\eta_{m}=q_{0} K_{e} m N_{1} N_{2} \cos \alpha
$$

where: $m$ - extracting capacity of the seam, m; $\alpha$ - dip angle of the seam, deg.; $N_{l}$ and $N_{2}$ - the rates of array's undermining; $q_{0}$ - respective value of maximum subsidence.

The ratio of equivalent extracting capacity $K_{e}$ can be defined on the results of the instrumental observations and using empirical formula (2):

$$
K_{e}=\frac{B_{k}}{B_{k}+B_{c h}} ;
$$

where: $B_{k}$ - the width of extracting chamber, $\mathrm{m} ; B_{c h}-$ the width of inter-chamber pillar, $\mathrm{m}$

The rates of array undermining $N_{l}$ and $N_{2}$ are obtained for Kuzbass conditions through approximation.

According to the results of instrumental observations the distribution function of the Earth's surface subsidence was determined (a typical curve of subsidence, Fig. 6), in the cauldron along the strike of the seam in the relative values given to the interval $[0,1]$.

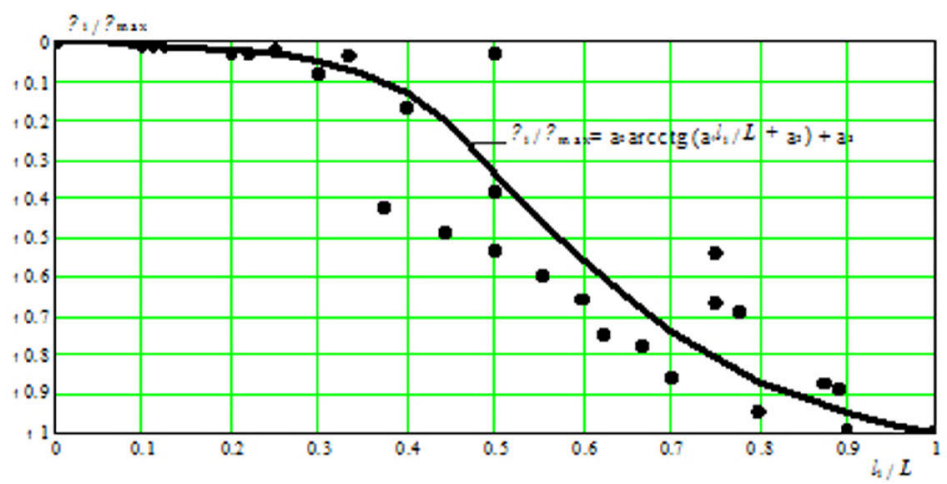

Fig. 6. The distribution function of Earth's surface subsidence in the subsidence of the main section along the strike of the formation. 
Defined function of subsidence distribution was approximated by formula (3):

$$
\frac{\eta_{i}}{\eta_{m}}=a_{0} \operatorname{arcctg}\left(a_{1} \cdot \frac{l_{i}}{L_{s}}+a_{2}\right)+a_{3}
$$

where: $L_{s}$ - the cauldron of subsidence in the main section along the strike of the seam, $\mathrm{m} ; \eta_{i}, l_{i}$ - current values of subsidence and cauldron's length respectively, $\mathrm{m}$.

Empirical rates $a_{0}, a_{1}, a_{2}, a_{3}$ were defined using aggregate statistical method of the least squares.

The cauldron across the strike was calculated using formula (4):

- for incomplete undermining: $\left(N_{2}<1\right)$ :

- for complete undermining $\left(N_{2}=1\right)$ :

$$
L_{s}=h_{c} \operatorname{ctg} \varphi+\left(H_{a v}-h_{c}\right) \operatorname{ctg} \delta+\frac{D_{2}}{2},
$$

$$
L_{s 3}=h_{c} \operatorname{ctg} \varphi+\left(H_{a v}-h_{c}\right) \operatorname{ctg} \delta+H_{a v} \operatorname{ctg} \psi_{3}
$$

where: $H_{a v}$ - the thickness of cap rock, $\mathrm{m} ; \varphi=55^{0}$ - the angle of displacement for dry and normal humidity cap rock; $\varphi=45^{\circ}$ - for quicksand and water-bearing gravel; for Kuzbass: $\delta=80^{\circ}, \Psi_{3}=50^{\circ}$.

\section{Conclusion}

According to methodical provisions proposed in this paper, SIGI Institute developed the algorithm of calculating of the Earth's surface expected displacements and deformations by the complex of coal seams deep processing. With the accumulation of instrumental observations the calculation algorithm will be updated.

\section{References}

1. B.G. Saksin, I.Y. Rasskazov, J. Min. Sci., 51(2), 134 (2015)

2. G.G. Kocharyan, A.A. Ostapchuk, J. Min. Sci.,, 51(1), 87 (2015)

3. A.A. Mylnikova, Yu.V. Yasyukevich, E.V. Kunitsyu, Results in Physics. 5, 65 (2015)

4. C. DeMets, R.G. Gordon, D.F. Argus, Geophys. J. Int., 181, 89 (2010)

5. R. McCaffrey, J, Geophys. Res., 110, 07401(2005)

6. P. Bird. Geochem. Geophys. Geosys. 4(3), 33 (2003) 